\title{
ON CERTAIN BLOOD CHANGES IN IDIOPATHIC EPILEPSY.
}

BI ROBERT PUGH, M.D.EDIN.

Assistant Nedical Officer, London County Asylum, Claybury.

THE following research was suggested to the writer by Dr. F. W. Mott, and the work has been carried out in the laboratory of the London County Council, Claybury; the clinical material was obtained from Claybury Asylum. The writer desires to express his deep indebteduess to Dr. Mott for having suggested the investigation, for the use of the Claybury laboratory and for numerous practical hints; to Dr. J. S. Bolton for his assistance and suggestions, and to Dr. Robert Jones for permission to use the clinical material in the Asylum, and for the facilities which be afforded him to obtain it.

In all, forty cases have been investigated, and in twenty of these a differential count of the leucocytes has been made. In all the cases the alkalinity of the blood has been estimated, and in some of the cases the effect of different drugs on the alkalinity has been determined.

The paper commences with a historical account of the previous work which has been done on the subject, and this is followed by a description of the method which has been used during the present research; an account of the cases which have been used and the results which have been obtained are then introduced; and the paper concludes with a short summary of the results of the investigation.

\section{The Alralinity.}

Under normal conditions the reaction of buman blood is alkaline. The allialinity is due to the presence of two salts, e.g., bicarbonate of soda $\mathrm{NaHCO}_{3}$ and disodic phosphate 
$\mathrm{Na}_{\mathrm{k}_{2}} \mathrm{HPO}_{4}$. These two salts are acid salts, and are readily dissociated when brought in contact with an indicator such as litmus, forming a coloured salt. Phenolphthalein when used as an indicator gives a neutral reaction owing to the fact that it does not possess the power of dissociating these acid salts, and for this reason it cannot be employed. Thus the blood is an alkaline fluid in virtue of these two salts, which are bases in combination with very weak acids.

\section{HISTORICAL.}

Up to the present time various investigations have been carried out, and different methods used to estimate the alkalinity of the blood. The earlier investigators used the titration method. Luntz (1) titrated with phosphoric acid; Lassar (2) titrated with oxalic acid. The same objections apply to both these methods-the amount of blood required is too large, and the solution of these organic acids becomes weaker when exposed to light and air. Leibrich (3) used slabs of plaster of Paris impregnated with litmus-a drop of blood was applied to the slab-the blood corpuscles were retained on the surface. The plasma soaked in and reacted with the absorbed litmus. Schäfer used sheets of glazed paper impregnated with litmus.

These methods were improved upon by Landois (4) in 1884. As this method has been in extensive use it may be briefly described. Blood is mixed with a solution of sulphate of soda and titrated with tartaric acid, the neutral point being estimated with litmus paper. The principle of the method consists in the prevention of coagulation by the saline solution, while the alkalinity is neutralised by the titration with tartaric acid, thus 7.5 solution of tartaric acid is added in graduated amounts to the sulphate of soda solution. Solution 1 will contain $\frac{100 \text { ectid }}{10 \text { sulphato }}$, solution 2

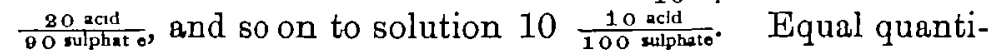
ties of blood and one of these solutions are taken up in a pipette, and thoroughly mixed in a watch-glass, and the reaction tested with litmus paper. If the mixture is alkaline, then the next strongest acid solution is taken, and so on until the neutral point is obtained. 
Drouin improved this method by titrating with oxalic acid. Again the objection is that too much blood is required, also the presence of the red blood corpuscles necessitates dilution with the saline solution, thus increasing the difficulty of accurately estimating the neutral point. In this method the alkalinity of the blood plasma and corpuscles is estimated, and in order to do this efficiently, titration must be carried out slowly and at the body temperature, so that all the corpuscles are broken down.

Haycraft and Williamson's method (5) consists of a series of glazed litmus paper treated with different strengths of sulphuric acid. This gives a series of papers of graduated acidity. A drop of blood is brought in contact with a paper of a certain strength for ten seconds, then dipped in water, and the reaction noted. The method is a simple one, but the results are not accurate enough.

Wright's method (6), which is used in this investigation and described in full. Wright claims many advantagesthe quantity of blood required is small, the red blood corpuscles are completely separated from the serum, the alkalinity can be tested in a few hours, and from a clinical point of view the alkalinity of the serum is the more important because it comes into such close contact with the tissues, and may be taken as an index to the changes taking place in the circulating blood.

\section{Phirsiology.}

The alkalinity undergoes a diurnal variation, being lowest in the morning, gradually rising in the afternoon, and becoming less again in the evening (7). It is increased during digestion, owing to the passage of bicarbonate of soda from the stomach to the blood. It is decreased after severe muscular exertion, probably owing to the entrance of the products of muscular metabolism, e.g., sarcolactic and carbonic acids, into the blood. Apart from these two conditions, the alkalinity is maintained at a constant level, varies within physiological limits, and may be taken as an index of the amount and activity of oxidation within the tissues. 


\section{Pathology.}

Numerous observations are recorded, noting the changes in the alkalinity in disease. These changes are constant, and manifest themselves in a diminution of the alkalinity, in diseases of the blood, e.g., leucocythæmia and pernicious anæmia; in febrile and cachetic conditions; in diabetes; and especially in diabetic coma, cholera, jaundice, gout, and rheumatism. Also in certain mental diseases, e.g., dementia paralytica, and epilepsy.

Charon and Biche (8), working with Landois' method, found a diminution in epilepsy, and came to the conclusion "that the epileptic attacks present nearly constant variations and in inverse relationship to the variations in the alkalinity of the blood."

Lui (9), a year later, confirmed the diminution in the alkalinity.

\section{Wright's Method.}

The thumb is cleansed with soap and water and sterilised with 5 per cent. solution of formalin-a solution of carbolic acid is inadmissible, as it interferes with the alkalinity of the blood. An incision is then made with a lancet, and a copious supply of blood is obtained; it is unnecessary to apply pressure to the thumb. The blood is collected in capillary tubes by means of gravity and capillary attraction, or if necessary by suction at the other end of the tube.

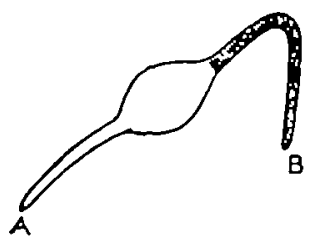

B is then sealed up in the blowpipe flame, the tube inverted, then $A$ is sealed. It may be left suspended for twenty-four hours, during which the clear plasma will 
gravitate to the $A$ end, the corpuscles being retained at the $B$ end. The method used by the writer was to suspend the tube for some hours, and then to centrifuge.

\section{Preparation of Acid Solutions and Indicator for the Analyses.}

A solution of sulphuric acid is accurately standardised by precipitating with barium chloride and weighing the barium sulphate thus produced. The motber solution used is of the following value : 1 cc. $=\cdot 04155$ grammes of $\mathrm{H}_{2} \mathrm{SO}_{4}$ (mean of six analyses). Dilutions of various strengths are made from this acid by running the calculated amount for the strength from the burette into a graduated cylinder and adding the requisite amount of distilled water. The dilutions first used were $10,20,30,40,60$. These were supplemented by other dilutions as these became necessary during the progress of the investigation.

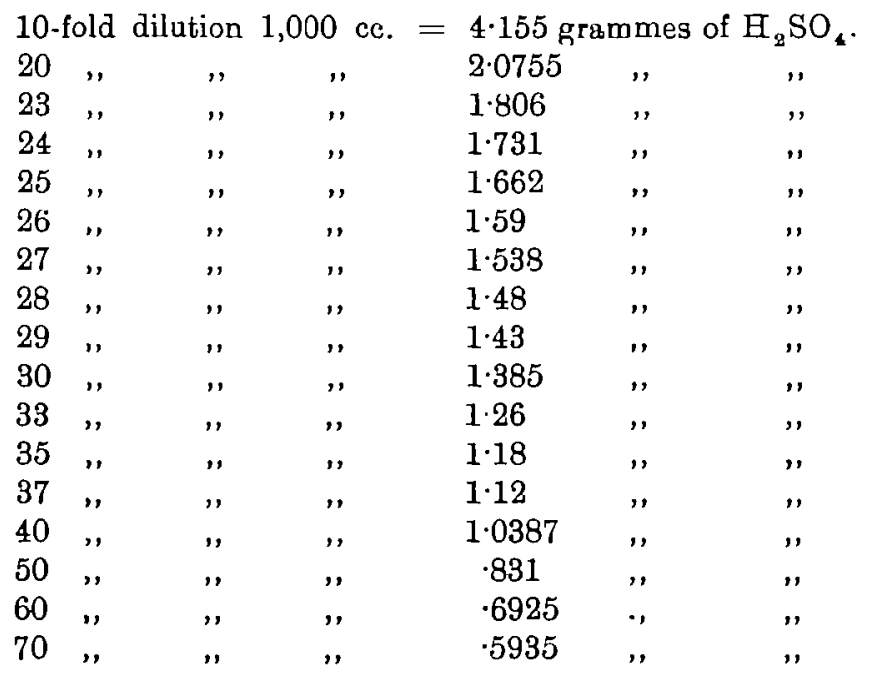

The indicator used was the No. 6 special litmus paper of Grübler. This was treated according to Wright with an extremely dilute acid solution ( 1 in 20,000 of hydrochloric acid), washed with distilled water, and dried at $100^{\circ} \mathrm{C}$. 
Titration of Serum against the Standard Acid Solutions.

A capillary pipette is inserted into the serum, and the latter is allowed to flow into the tube for a distance of $2 \mathrm{~cm}$. The serum is allowed to run up the pipette for a short distance in order to introduce an air bubble, and then a mark is made with a blue pencil. The end of the pipette is now quickly inserted into a solution of acid of a known strength, say the 30 -fold dilution, and the acid solution is allowed to run in until the lower end of the serum column runs up to the blue mark. In this way an equal quantity of serum and of an acid of known strength is obtained. The contents of the pipette are blown out on to a clean watch glass and thoroughly mixed with the end of the pipette, aspirated, blown out again, and so on until mixing is complete. Finally the mixture is once more taken into the pipette, and a drop or two are blown on to a piece of the prepared litmus paper. The reaction is noted, and if the neutral point has not been accurately estimated fresh titrations are carried out with acids of greater or less strength until the desired reaction is obtained. Great care must be taken to standardise the acid in the first instance. Wright's results are given as dilutions of the chemically normal $\mathrm{H}_{2} \mathrm{SO}_{4}$ acid, but the acid employed in this investigation was of different strength, thus :-

$$
\begin{aligned}
& 1,000 \text { cc. }=4.155 \text { grammes of } \mathrm{H}_{2} \mathrm{SO}_{4} \\
& 1,000 \text { cc. }=4.9 \text { grammes of } \mathrm{H}_{2} \mathrm{SO}_{4} \text { (Wright's). }
\end{aligned}
$$

The alkalinity has been returned as the amount of $\mathrm{H}_{2} \mathrm{SO}_{1}$ in 1,000 cc. of the acid solution employed, which would exactly neutralise $1,000 \mathrm{cc}$. of serum. Thus, by alkalinity 1.385 is meant that 1,000 cc. of a solution containing this amount of $\mathrm{H}_{2} \mathrm{SO}_{4}$ would exactly neutralise the alkaline properties of $1,000 \mathrm{cc}$. of the serum.

For obtaining the normal alkalinity control cases bave been selected from the staff of Claybury Asylum-physicians, clerks, porters, and attendants. Care was taken to avoid the time during which the alkalinity is said to vary, e.g., after food and after severe muscular exercise. Blood was taken at a stated time, 11 a.m., on successive days from each case. 
The average obtained was 1,662; one case, W. H. F., showed the highest, 1,806; this was obtained on three occasions. In all twenty cases were examined. The control cases were not taken from one class in order to show the constancy of the alkalinity, for in spite of the different conditions of living, such as diet, habits, \&c., between the cases, the alkalinity was maintained at a constant value, and varied within physiological limits.

In the case of the epileptics, blood was taken from each patient at 11 a.m. On successive days daring the interparoxsymal period, i.e., an interval of seven days between seizures. The alkalinity varied ; two cases showed a normal alkalinity. The average of the forty cases was below that of the control cases.

\section{LEUCOCYTES.}

The blood was obtained from the ear in nearly all the cases, and from the thumb in the remainder. 'The instrument ased for the leucocyte count was the ordinary Thoma-Zeiss apparatus; the diluting fluid was the ordinary normal saline solution coloured with methyl violet. In all the cases 256 squares were counted, the co-efficient of error being 2 per cent. Cover glass preparations were taken at the same time, put in the incubator for an hour, held over osmic acid vapour for five minutes, replaced in the incubator for twenty-four hours, then stained with well-diluted Delafield's hømatoxylin for five minutes, counterstained with eosin for thicty seconds, washed in methylated spirit, absolute alcohol, cleared in xylol, and mounted. In the differential count from 800 to 1,000 leucocytes were counted ; four cover glass preparations were used. The nomenclature adopted in the classification of the leucocytes is taken from Clifford Allbutt's "System of Medicine."

(I.) The finely granular oxyphil polymorphonuclear contains numbers of fine granules - nucleus irregular and multipartite, phagocytic, 75 per cent.

(II.) The coarsely grauular oxyphil or eosinophile contains large granules-nucleus, horseshoe, or vermiform, not phagocytic, 2 per cent. 
(III.) Small hyaline or lymphocyte-nucleus large, protoplasm byaline, no grauules, 20 per cent.

(IV.) Large hyaline, larger amount of protoplasm than the small, 10 per cent.

The total number of leucocytes per cubic millimetre of blood is extremely variable-variations occur in normal individuals at different times-the normal range lies between 6,000 and 10,000. Any number below 6,000 constitutes a bypo-leucocytosis, and above 10,000 a leucocytosis. Physiological lencocytosis occurs in the new-born, in pregnancy, and during digestion. As all the cases are males and adults, the first two are excluded. In taking the leucocyte count in the interparoxysmal period, due attention was paid to the last point, and the time chosen was balf an hour before meals, digestion leucocytosis thus being ruled out.

\section{Historical.}

Rutberford Macphail (11) was the first observer to note the changes in the blood in mental diseases. He states that in epilepsy the vitality is lowered and the blood is more deteriorated in male than in female patients. Of 100 cases on admission 37 per cent. recorded a lower percentage of red blood corpuscles and 40 per cent. showed a bigher percentage than normal ; the leucocytes varied within physiological limits. Kroumbmiller (12) who studied the blood in various psychoses, which included twelve cases of epilepsy, states that at the time of the attack the total quantity of leucocytes increases, and that this increase diminishes with every new attack ; the leucocytosis is at its highest an hour after the attack. The increase is due to a relative and absolute increase of lymphocytes with a relative decrease of the older cells. He also states that a few hours after the paroxysm the coarsely granular oxyphil cells are increased.

Case 1.-Aged 16, admitted May 31, 1900; duration of epilepsy five years, bodily condition good.

Family history.-Father and mother alive, intemperate. Paternal aunt insane, patient the only child.

Mental condition.-Very dull and feeble-minded, is unable to 
add simple numbers, slow in answering questions. After fits is very impulsive and restless. Often has to be held down.

History of fits.-First fit five years ago, when at school. Fits gradually increased in frequency, grand mal; aiter an attack remains in a state of mental confusion for some hours (five to fourteen).

Record of fits from admission to December 31, 1901.-Day fits 110 ; night fits 207.

Alkalinity of blood during the interval $1 \cdot 48$.

September 24, 1901.-Seven fits from 8 p.m. to 9.50 p.m. Blood 10 p.m. alkalinity $1 \cdot 0387$. Blood 10.30 p.m. alkalinity 1.26. Blood 11 p.m. alkalinity 1.385. Blood 12 p.m. alkalinity 1.385. Blood 1 a.m. alkalinity $1 \cdot 43$.

The next morning patient was very confused. Blood 10.30 a.m. alkalinity $1 \cdot 43$.

December 20, 1901.-Five fits fromi 7 a.m. to 7.45 a.m. Blood 9 a.m. alkalinity $1 \cdot 18$. Blood 11 a.m. alkaliuity $1 \cdot 43$. Blood 12 a.m. alkalinity $1 \cdot 48$. Blood 3 p.m. alkalinity $1 \cdot 48$.

December 25, 1901.-Five fits from 10 a.m. to 12 noon. Blood 12.30 p.m. alkalinity 931 . Blood 1.30 p.m. alkalinity $1 \cdot 12$. Blood 2.30 p.m. alkalinity $1 \cdot 385$. Blood 5.30 p.m. alkalinity $1 \cdot 43$.

The patient was very confused, would not answer questions, and was very irritable when spoken to.

This mental confusion lasted for eight days, and during this period blood was taken at a stated time-11 a.m. every morning. December 26, alkalınity 1.48; December 27, alkalıity 1.48; December 28, alkalinity 1.48; December 29, alkalinity 1.538; December 30 , alkalinity 1.48 ; December 31 , alkalinity 1.59 ; January 1, alkalinity 1.59 ; January 2, alkalinity $1 \cdot \dot{0} 9$.

On January 3 he was bright and cheerful, answered questions readily and expressed a desire to get up. From December 20 to January 3, he was not trented for his eplepsy.

January 5.-Was put on potas. bromid. gr. 20, tbree times a day. This treatment was continued until January 13. Daring this treatment he had three day fits, and the alkalinity was maintained at 1.538 .

January 12, 1902.-A About eixty seconds after his blood had been taken, he had a slight fit. Immediately prior to the fit, alkalinity 1.26 ; half an hour after, alkalivity 1.18 ; one hour after, alkaliuity 1.385 ; two hours after, alkalinity 1.43 ; four hours after, alkalinity $1 \cdot 538$.

January 13, 1902. - Was put on suprarenal extract, one capsule three times a day after meals; on the 15th the dose wis increased to six per diem. On the 20 th reduced to three a day, 
and continued until January 29 . Whilst under this treatment he had thirty-three day fits and seventeen night fits, which is a distinct increase; the mental confusion, however, was not so great, and he recovered from the after-effects of the paroxysms much sooner than when under the bromide treatment. During the intervals, there were no distinct changes in the blood; the leucocytes appeared normal, the alkalinity was not affected, the pulse was diminished in frequency by eight beats, and the blood pressure was increased.

January 30.- $\mathrm{He}$ was given strontii bromid. gr. 15, sodii bicarb. gr. 15, aq. ad $\bar{\jmath}$, 3 j three times a day. This treatment was continued for two months. During this time he had four day fits and seventeen night fits, which is a pronounced decrease, the average number of fits per month being six day fits, ten night fits. The alkalinity was maintained at a fairly constant value, and varied from 1.48 to 1.662 .

Leucocytes. - Interparoxysmal period, 9,500. Differential count:-Polymorphonuclear, 65 per cent.; large hyaline, 6 per cent.; small hyaline, 25 per cent.; eosinophile, 3 per cent. Ten minutes after seven fits:-Leucocytes, 10,000. Differential count:-Polymorphonuclear, 68 per cent.; large byaline, 8 per cent.; small hyaline, 23 per cent.; eosinophile, 4 per cent. Sixty minutes later :-Leucocytes, 21,000. Differential count :Polymorphonuclear, 60 per cent. ; eosinophile, 5 per cent.

Case 2.-Aged 18. Admitted August 7, 1900. Duration of epilepsy, nine years; bodily condition good.

Family history.-Father died of acute Bright's disease aged 36, an alcoholic. Mother alive and well; six children, four boys, two girls; patient is the fifth child; the sixth child is also an epileptic.

Mental condition.-Is rational in manner and talk, slight impairment of memory; is very intractable after fits.

History of fits.-Developed his epilepsy at nine years of age ; his mother states that he had a fall on his head when six years of age. Grand mal. Recovery from mental confusion gradual ; two minutes before a fit the right lower eyelid twitches.

Record of fits from admission to December 31, 1901.-Day fits, 44 ; night fits, 81.

Alkalinity in the interparoxysmal period, 1.538. Slight fit 8 a.m. Blood 11 a.m. alkalinity 1.385. Blood 2.30 p.m. alkalinity 1.538 .

Two fits 9.30 p.m. Blood 10.30 p.m. alkalinity 1.26 . Blood 11.30 p.11. alkalinity 1.385. Blood 1 a.m. alkalinity $1 \cdot 48$. 
Blood 7.30 p.m. alkalinity $1 \cdot 59$. Blood 11 a.m. alkalinity $1 \cdot 43$. Blood 12 noon alkalinity $1 \cdot 48$. Blood 3 p.m. alkalinity 1.48 .

January 12, 1902.-About sixty seconds after his blood had been taken he had a slight fit.

Immediately prior to the fit, alkalinity 1.26 ; half an bour after, alkalinity $1 \cdot 18$; one hour after, alkalinity 1.385 ; two hours after, alkalinity 1.43 ; four hours after, alkalinity 1.538 .

Leucocytes.-The study of the blood ten minutes after the fit shows leucocytes 9,500. An hour after:-There is a distinct leucocytosis 14,000. Differential count:--Polymorphonuclear, 60 per cent.; small hyaline, 25 per cent.; large hyaline, 11 per cent. ; eosinophile, 4 per cont.

Case 3.-Aged 18. Admitted August 24, 1900. Duration of epilepsy, fourteen years. Bodily condition fair, stature short, suffers from constipation.

Family history.-Father and mother (Jews) dead, both intemperate; patient the only son; one sister alive and healthy. Maternal uncle insane, committed suicide.

Mental condition.-Is simple and childish in manner and talk, is easily confused, mental reaction slow. Answers questions slowly. Memory for recent events impaired.

History of fits. - Said to be bealthy and intelligent up to 1886 , when his father died suddenly. Soon after this patient had two epileptic fits. Grand mal. Mental confusion lasts about one and a half hours.

Record of fits from admission to December 31, 1901.-Day fits, 275 ; night fits, 450 .

Alkalinity in the interparoxysmal period, $1 \cdot 48$.

December 2.-Eight fits from 10.30 a.m. to $11 \mathrm{a.m}$.

Blood 11.15 a.m. alkalinity 831 . Blood 12 noon alkalinity 1.26. Blood 1 p.m. alkalinity 1-385. Blood 3 p.m. alkalinity $1 \cdot 48$.

At 4 p.m. patient was very restless and inritable, and a little confused. At 7.30 he had ten very severe fits, and was given an enema of potas. brom. gr. 30 , chloral hydrate. gr. 15 .

Blood 7.45 p.m. alkalinity $1 \cdot 18$. Blood 8.30 p.m. alkalinity 1.385. Blood 9.30 p.m. alkalinity $1 \cdot 26$. Blood 11.30 p.m. alkalinity $1 \cdot 48$.

Daring the month of December the potassium bromide was suspended, and he had 97 day fits and 41 night fits.

December 15.-Fifteen fits 11.50 p.m. to 12.30 a.m.

Blood 12.40 a.m. alkalinity $\cdot 831$. Blood 1 a.m. alkalinity 1.26. Blood 10.30 a.m. alkalinity $1 \cdot 538$. 
December 21. - Fourteen fits 8.30 p.m. to 9 p.m.

Blood 9.15 p.m. alkalinity $1 \cdot 0387$. Blood 10 p.m. alkalinity 1.385. Blood 11 p.m. alkalinity $1 \cdot 43$. Blood 12 midnight alkalinity $1 \cdot 48$.

January 13, 1902.-Was put on suprarenal extract, one capsale three times a day after meals. On the 17 th the dose was increased to six per diem; on the 22nd the dose was reduced to three per diem. This treatment was continued until February 1. The effects produced were essentially similar to those produced in Case 1. The fits increased in frequency; the record for the eighteen days reads :-11 day fits, 154 night fits. The marked increase of the nocturnal fits is very striking, and is five-fold greater than the average monthly record. The nearest approach to these figures was in June, 1901, when the patient had 121 night fits.

Blood.-No distinct change in the alkalinity, which varied from 1.48 to 1.538 . The leucocytes appeared normal.

Pulse.-Diminished in frequency by nine beats on an average, and the blood pressure was increased. January 14, 11 a.m., $125 \mathrm{~mm}$. January 16, 11 a.m., $130 \mathrm{~mm}$. January 18, 11 a.m., $130 \mathrm{~mm}$. January 21, 11 a.m., $145 \mathrm{~mm}$. January 26, 11 a m., $145 \mathrm{~mm}$.

The effect upon the mental state was good, and the recovery from the confusion following the fit was rapid.

January 30, 1902. - He was put on strontii bromidi gr. 15, sodii bicarb. gr. 15, aq. ad $3 j$, 3 j, three times a day.

February 12.-The mixture was given four times a day for twelve days, and from February 24 to the end of March three times a day. Under this treatment the number of fits was considerably decreased, and during the month of February the patient did not have a fit. The alkalinity was maintained at a constant value, e.g., 1.538 to 1.662 .

Leucocytes. - Interparoxysmal period, 9,200. Differential count :-Polymorphonuclear, 68 per cent. ; large byaline, 7 per cent. ; small hyaline, 22 per cent.; eosinophile, 3 per cent. Forty minutes after eight fits:- Leucocytes, 19,000. Differential count :-Polymorphonuclear, 60 per cent.; large hyaline, 8 per cent. ; small hyaline, 30 per cent. ; eosinophile, 2 per cent.

Case 4.-Aged 19, admitted May 15, 1900. Duration of epilepsy, seven years. Bodily condition good.

Family history.-Father and mother alive and well. Insanity and phthisis on mother's side. Patient the only child alive; his brother died of phthisis, aged 18 . 
Mental condition. - Is rational in manner and talk in the intervals. Memory slightly impaired. Is very fanciful and restless after fits, and develops delusions of persecution.

History of Fits.-Developed epilepsy at 12 years of age; the fits gradually increased in frequency; the month before admission he had over 100 fits. Grand mal, mostly nocturnal ; recovery from mental confusion rapid.

Record of fits from admission to December 31, 1901.-Day fits, 693 ; night fits, 830 .

Alkalinity in the interparoxysmal period, 1.43 ; three hours after his blood had been taken the patient had a strong fit-3 p.m. Blood 3.15 p.m. alkalinity 1.0387. Blood 4 p.m. alkalinity 1.26. Blood 5 p.m. alkalinity $1 \cdot 43$. Blood 8 p.m. alkalinity 1.538 .

January 13, 1902.-Was put on suprarenal extract, one capsule three times a day. On the 17 th the dose was increased to six a day. This treatment was carried out for eighteen days. The fits increased in frequency, but not to such an extent as in Cases 1 and 3. There were no distinct changes in the blood, the leucocytes were normal, but the alkalinity varied; on two occesions it was 1.43.

Pulse.-Diminished in frequency by six beats, the blood pressure was increased. The effect upon the mental state was very pronounced, the after-effects passing off in a short time.

Letcocytes. - Interparoxysmal period, 10,000. Differential count:- Polymorphonuclear, 70 per cent.; large hyaline, 6 per cent. ; small hyaline, 21 per cent. ; eosinophile, 3 per cent. Four hours after a fit:-Leucocytes, 12,000 Differential count :Polymorphonucleur, 62 per cent.; large hyaline, 4 per cent.; small hyaline, 30 per cent. ; eosinophile, 5 per cent.

Case 5.-Aged 33, admitted October 18, 1893. Duration of epilepsy unknown. Bodily coudition fair.

No family history obtained.

Mental condition.-Is dull, lost, and feeble-minded. After tits is restless, and has ballucinations of sight.

History of fits.-Grand mal. Epigastric auru. Mental confusion lasts about three hours.

Record of fits from admission to December 31, 1901.-Day fits, 305 night fits, 448.

Interparoxysmal alkalinity, 1.662, 1.538. Five fits in quick succession. Blood fifteen minutes after, alkalinity 831 . Blood one hour after, alkalinity 1.26. Blood two hours after, alkalinity 1.385. Blood four hours after, alkalinity 1.48. Blood twelve hours after, alkalinity 1.662. Alkalinity during aura, 1.26. 
Lerucocytes.-Twelve hours after five fits:-Leucocytes, 11,000 . Differential count:--Polymorphonuclear, 70 per cent.; large hyaline, 7 per cent.; small hyaline, 18 per cent.; eosinophile, 5 per cent.

Case 6.-Aged 46, admitted September 10, 1896. Duration of epilepsy three years. Bodily condition fair.

Family History.-Father and mother dead. Paternal uncle insane. Patient the only child.

Mental condition.-Is demented; has very little idea of time or place; after fits is very restless and irritable, and develops religious delusions.

History of fits.-Had his first fit three years ago after a drinking bout. Grand mal. Mental confusion lasts about three hours.

Record of fits from admission to December 31, 1901.-Day fits, 81 ; night fits, 114.

Interparoxysmal alkalinity, 1.662 to 1.538 . Two strong fits. Blood 20 minutes after, alkalinity 1.0387. Blood half an hour after, alkalinity $1 \cdot 12$. Blood one hour after, alkalinity 1.26. Blood two hours after, alkalinity 1.43. Blood five hours after, alkaliuity 1.538 .

Sixty minutes after:-Leucocytes 18,000. Differential count :Polymorphonuclear, 58 per cent.; large hyaline, 8 per cent.; small hyaline, 33 per cent. ; eosinophile, 2 per cent.

Case 7.-Aged 40, admitted May 25, 1895. Duration of epilepsy, ten years; bodily condition good.

Family history.-Father died of pneumonia, an alcoholic; motber alive and healthy; two brothers alive and well.

Mental condition.-Very rambling and incoherent in talk. Memory much impaired especially for recent events; expresses "electrical" delusions.

History of fits.-Bad his first fit when 30 years of age, at which time he was travelling with a circus; no history of drink. Grand mal ; mental confusion lasts about three hours.

Record of fits from admission to December 31, 1901.-Day fits, 332 ; night fits, 328.

Interparoxysmal alkalinity, 1.538. Slight fit 10.40 a.m. Blood 11.5 a.m. alkalinity $1-18$. Blood 11.45 a.m. alkalinity 1.26 . Slight fit 12.10 p.m. Blood 12.30 p.m. alkalinity 1.0387 . Blood 1.30 p.m. alkalinity 1.26 . Blood 3.30 p.m. alkalinity $1 \cdot 43$. Blood 5.30 p.m. alkalinity 1.538 .

Fifty minutes after the second fit:-Leucocytes 19,000 . 
Differential count :-Polymorphonuclear, 59 per cent.; large hyaline, 30 per cent.; small hyaline, 30 per cent.; eosinophile, 3 per cent.

Case 8.-Aged 19, admitted August 8, 1900. Daration of epilepsy, three years. Bodily condition good.

Family history.-Father died of heart disease, intemperate. Mother alive and healthy. Maternal uncle died of phthisis. Patient was the only child.

Mental condition.-Is very unstable, restless, and irritable, and is given to introspection; after fits is pugnacious, intractable and suicidal.

History of fits. - Had his first fit when 16 years old, then had a fit every week for six weeks, and then ceased having them for eight weeks. The fits gradually increased in frequency and severity. Grand mal. Recovers quickly from the mental confusion.

Record of fits from admission to December 31, 1901.-Day fits, 94 ; night fits, 236.

Interparoxysmal alkalinity $1 \cdot 538$.-Fit 11.30 a.m. Blood $11.40 \mathrm{a} . \mathrm{m}$. alkalinity $1 \cdot 12$. Blood 12.30 p.m. alkalinity $1 \cdot 385$. Blood 1.30 p.m. alkalinity 1.48 . Blood 3.30 p.m. alkalinity 1.538 .

Forty minutes after two fits :-Leucocytes, 17,000. Differential count:--Polymorphonuclear, 60 per cent.; large hyaline, 29 per cent.; small hyaline, 10 per cent. ; eosinophile, 1 per cent.

Case 9.-Aged 25, admitted December 28, 1900. Duration of epilepsy, fifteen years. Bodily condition good.

Family history.-Father and mother alive and healthy, both intemperate. 'Two brothers alive and healthy. Patient the third child. One sister simple-minded.

Mental condition.-After fits is very impulsive, religious and emotional. Slight mental impairment.

History of fits.-Developed his epilepsy at 10 years of age. The fits gradually increased in frequency. Grand mal. Laryngeal aura. Recovery from mental confusion gradual (in about three hours).

Interparoxysmal alkalinity 1.538 ; forty seconds before fit 1.26 ; half an hour after, alkalinity 1.18 ; one hour after, alkalinity 1.385 ; two hours after, alkalinity 1.43 ; six hours after, alkalinity 1.538 .

Eighty minutes after one fit:-Leucocytes, 12,400. Differential count:-Polymorphonuclear, 68 per cent.; large hyaline, 23 per cent. ; small hyaline, 6 per cent. ; eosinophile, 3 per cent. 
Case 10.-Aged 31, admitted October 24, 1896. Duration of epilepsy, five years. Bodily condition good.

No family history obtained.

Mental condition.-Is dull, stupid, and feeble-minded. Memory very defective, has no ides of time. After fits is irritable, and develops persecutory delusions.

History of fits.-Grand mal. Mental confusion lasts about three hours.

Record of fits from admission to December 31, 1901.-Day fits, 954 ; night fits, 527.

Interparoxysmal alkalinity, 1.48. Fit 8 a.m. Blood 11 a.m. alkalinity $1 \cdot 385$. Blood 2.30 p.m. alkalinity 1.538 . Strong fit 2.45 p.m. Blood 3.30 p.m. alkalinity $1 \cdot 12$. Blood 4.45 p.m. alkalinity 1.385. Blood 8 p.m. alkalinity 1.538. Two fits 9 p.m. Blood 9.15 p.m. alkalinity $\cdot 831$. Blood 10 p.m. alkalinity $1 \cdot 12$. Blood 11 p.m. alkalinity 1-26. Blood 1 a.m. alkalinity $1 \cdot 48$.

Fifty minutes after the fit:-Leucocytes, 14,000 . Differential count:-Polymorphonuclear, 60 per cent.; eosinophile, 3 per cent. ; large hyaline, 8 per cent.; small hyaline, 30 per cent.

Case 11.-Aged 21, admitted February 2, 1900. Duration of epilepsy, eight years. Bodily condition fair; suffers from constipation and indigestion.

Family history.-Father alive and well. Mother died of cancer, aged 44. Epilepsy and phthisis on mother's side.

Mental condition.-Is simple in manner and talk; slight mental impairment. After fits is restless and irritable, and develops persecatory delusions.

History of fits.-Had his first fit when 13 years of age. Grand mal. Epigastric aura five minutes before the fit. Recovery from mental confusion gradual.

Record of fits from admission to December 31, 1901.-Day fits, 156 ; night fits, 107.

Interparoxysmal alkalinity, $1 \cdot 48$. Alkalinity during aura 1.385. Half an hour after fit, 1.18 ; one hour after fit, 1.385; two hours ufter fit, 1.48; four hours after fit, 1.538 .

Twelve hours after one fit:-Leacocytes, 9,000. Differential count:-Polymorphonuclear, 70 per cent; large hyaline, 7 per cent. ; small hyaline, 20 per cent.; eosinophile, 3 per cent.

Case 12.-Aged 46, admitted Angust 24, 1893. Duration of epilepsy, twenty years. Bodily condition good.

No family history obtained.

Montal condition.-Is very restless and irritable, and talks 
much and foolishly on religious subjects. Is very demented; has no idea of time or place.

History of fits.-Has very frequent petit mal seizures. Mental confusion lasts about an hour.

Record of fits from admission to December 31, 1901.-Day fits, 170 ; night fits, 27.

Alkalinity in the paroxysmal period, 1.538 . Alkalinity twenty seconds before a fit, 1.385. Fit 11 a.m. Blood 11.15 a.m. alkalinity $1 \cdot 385$. Blood 12.15 p.m. alkalinity 1448 . Blood 2 p.m. alkalinity 1.538. Three strong fits 7 p.m. Blood 7.20 p.m. alkalinity 831 . Blood 8 p.m. alkalinity $1 \cdot 12$. Blood 9 p.m. alkalinity 1.26. Blood 11 p.m. alkalinity 1.43. Blood 1 a.m. alkalinity 1.48 .

One hour after three fits:-Leucocytes, 23,000. Differential count:-Polymorphonuclear, 58 per cent.; large hyaline, 8 per cent.; small hyaline, 32 per cent.; eosinophile, 3 per cent.

Case 13.-Aged 49, admitted November 22, $1897 . \quad$ Duration of epilepsy, 43 years. Bodily condition fair, suffers from constipation and gastric catarrh.

Family history.-Father died in an epileptic fit. Mother alive, intemperate; maternal aunt insane.

Mental condition.-Is dull, stupid, and very demented. After fits is restless, irritable, and impulsive.

History of fits.-Herd his first fit when six years of age. He did not have a second until fifteen years later. This was followed by another four years afterwards, then they became nore fre. quent. Grand mal, no aura. Mental confusion lasts about four hours.

Record of fits from admission to December 31, 1901 :-Day fits, 32 ; night fits, 117.

Interparoxysmal alkalinity, $1.538: 1 \cdot 48$. Two fits 8.30 p.m. Blood 9 p.m. alkalinity $1 \cdot 12$. Blood 10 p.m. alkalinity $1 \cdot 26$. Blood 12 midnight alkalinity 1.43 . Blood 1 a.m. alkalinity $1 \cdot 48$.

One and a half hours after one fit:-Leucocytes, 20,000. Differential count :'-Polymorphonuclear, 58 per cent.; large hyaline, 6 per cent.; small hyaline, 39 per cont.; eosinophile, 2 per cent.

Case 14.-Aged 22. Admitted August 22, 1896. Duration of epilepsy, ten years. Bodily condition fair.

Family history.-Father and mother alive and healthy. One brother alive and well.

Mental condition.-Is dull, slow, and feeble-minded. Memory 
for recent events defective. After fits is dazed, destructive, and impulsive.

History of fits.-Developed his epilepsy when twelve years of age. Grand mal. Has a severe frontal headache balf an hour before the fit. Mental confusion lasts about four and a half hours.

Record of fits from andmission to December 31, 1901 :-Day fits, 445 ; night fits, 834.

Interparoxysmal alkalinity, $1 \cdot 538: 1 \cdot 48$. Four fits from 10 a.m. to 11 a.m. Blood 11.30 a.m. alkalinity $1 \cdot 12$. Blood 1 p.m. alkalinity $1 \cdot 385$. Blood 3 p.m. alkalinity 1.48. Blood 6 p.m. alkalinity $1 \cdot 59$. Alkalinity during aura, $1 \cdot 385$.

Six hours after four fits :-Leucocytes, 11,000. Differential count:-Polymorphonuclear, 61 per cent.; large hyaline, 6 per cent.; small hyaline, 25 per cent. ; eosinophile, 8 per cent.

Case 15.-Aged 28. Admitted January 25, 1900. Duration of epilepsy, twenty-two years. Bodily condition good.

Family history.-Father alive, very intemperate. Mother dead, cause unknown. Maternal uncle died of paralysis.

Mental condition.-Is very feeble-minded. Memory defective, has no idea of time. After fits is irritable, and has hallucinations of sight.

History of fits.-Developed his epilepsy when six years old. Grand mal. No warning. Mental confusion lasts about three hours.

Record of fits from admission to December 31, 1901.-Day fits, 105 ; night fits, 172.

Interparoxysmal alkalinity, 1.538. One severe tit 8.30 p.m. Blood 9 p.m. alkalinity 1.26 . Blood 10 p.m. alkalinity $1 \cdot 385$. Blood 11 p.m. alkalinity 1.48 . Blood 1 a.m. alkalinity 1.59 .

Twenty-four hours after two fits:-Leucocytes, 9,000. Differential count:-Polymorphonuclear, 70 per cent. ; large hyaline, 4 per cent. ; small hyaline, 23 per cent. ; eosinophile, 3 per cent.

Case 16.-Aged 31. Admitted December 8, 1899. Duration of epilepsy not known. Bodily condition fair, suffers from constipation.

Mental condition.-Is simple and childish in manner and talk; mental reaction slow, memory very defective.

History of fits.-Grand mal, no aura; mental confusion lasts about three hours.

Record of fits from admission to December 31, 1901.-Day fits, 16 ; night fits, 162. 
Interparoxysmal alkalinity, $1.538: 1.48$. Three fits, ten minutes' interval between the seizures. Blood half an hour after, alkalinity $1 \cdot 12$. Blood one hour after, alkalinity $1 \cdot 26$. Blood three hours after, alkalinity 1.48. Blood five hours after, alkalinity 1.59. Blood twelve hours after, alkalinity 1.59.

Eight hours after one fit:-Leucocytes, 8,000. Differential count :-Polymorphonuclear, 62 per cent.; lerge hyaline, 6 per cent. ; small byaline, 23 per cent. ; eosinophile, 9 per cent.

Case 17.-Aged 34, admitted August 15, 1893. Duration of epilepsy, seven years. Bodily condition fair.

No family history obtained.

Mental condition.-Is very dull and feeble-minded. Memory much impaired, has no idea of time. After fits is restless and intractable.

History of fits.-Ead his first fit seven yearg ago. Grand mal. No warning. Mental confusion lasts three hours.

Record of fits from admission to December 31, 1901.-Day fits, 490 ; night fits, 998 .

Interparoxysmal alkalinity, $1.59: 1 \cdot 48$. Ten minutes after two fits, alkalinity 1.0387. Thirty minutes after two fits, alkalinity 1·16. Two hours after two fits, alkalinity 1-385. Three hours after two fits, alkalinity 1.48 . Six hours after two fits, alkalinity $1 \cdot 59$.

Three days after one fit:-Leucocytes, 12,000. Differential count :-Polymorphonuclear, 56 per cent.; large hyaline, 7 per cent. ; small hyaline, 32 per cent. ; eosinophile, 5 per cent.

Case 18.-Aged 52, admitted September 30, 1896. Duration of epilepsy not known. Bodily condition fair.

No family history obtained.

Mental condition.-Is dull, stupid, and childish in manner and conversation. Memory much impaired. After fits has hallucinations of smell and becomes abusive.

History of fits.-Grand mal, no aura. Mental confusion lasts about three hours.

Record of fits from admission to December 31, 1901.-Day fits, 443 ; night fits, 313.

Interparoxysmal alkalinity, 1.538. Fit 1 p.m. Blood 2 p.m. alkalinity 1.26. Blood 3 p.m. alkalinity $1 \cdot 385$. Blood 5 p.m. alkalinity 1.48. Blood 7.30 p.m. alkalinity 1.59.

Three hours after two fits :-Leucocytes, 13,000. Differential count:-Polpmorphonuclear, 52 per cent.; large hyaline, 7 per cent. ; small hyaline, 38 per cent. ; eosinophile, 3 per cent. 
Case 19.-Aged 19, admitted March 8, 1900 . Duration of epilepsy, two years. Bodily condition good.

No family history obtained.

Mental condition.-Is very feeble-minded and is unable to read or write. Habits very faulty. Has very little idea of time or place.

History of fits. - Has always been dull and stupid. Had his first fit two years ago, and during the following twelve months had several slight seizures. A few months before admission he had numerous strong fits. Grand mal. Recovery from mental confusion gradual.

Record of fits from admission to December 31, 1901.-Day fits, 50 ; night fits, 55 .

Interparorysmal alkalinity, 1.538. Fit 11 a.m. Blood 12 noon alkalinity 1.385. Blood 1 p.m. alkalinity 1.43. Blood 3 p.m. alkalinity 1.48. Blood 7 p.m. alkalinity 1.59.

Four days after one fit:-Leucocytes, 9,000. Differential count:-polymorphonuclear, 68 per cent.; large hyaline, 8 per cent. ; small hyaline, 20 per cent. ; eosinophile, 4 per cent.

Case 20.-Aged 22, admitted October 18, 1894. Duration of epilepsy, 4 weeks. Bodily condition good.

No family history obtained.

Mental condition.-Is emotional and intractable; memory defective. After fits is intensely noisy, violent, and impulsive, and develops persecutory delusions.

History of fits.-Had his first fit four weeks prior to admission. Grand mal, epigastric aura. Mental confusion lasts about four hours.

Record of fits from admission to December 31, 1901.-Day fits, 303 ; night fits, 1,845 .

Interparoxysmal alkalinity, $1 \cdot 538: 1 \cdot 48$. Taken at 2 a.m., $1 \cdot 43$. Two fits in quick succession. Blood half an hour after, alkalinity 1.0387. Blood one hour after, alkalinity 126. Blood two hours after, alkalinity 1.43. Blood four hours after, alkalinity 1.59. Blood twenty-four hours after, alkalinity 1.59 .

Four hours after two fits:-Leucocytes, 14,000. Differential count :- Polymorphonuclear, 57 per cent.; large hyaline, 5 per cent.; small hyaline, 34 per cent.; eosinophile, 5 per cent.

Case 21.-Aged 26, admitted August 11, 1899. Duration of epilepsy thirteen years. Bodily condition good.

Family history. - Father and mother alive and healthy; two brothers living, healthy; one brother died abroad, cause unknown. Patient bas had syphilis. 
Mental condition. - Is simple and childish in manner. Does not appreciate his surroundings, is very demented, has very little idea of time.

History of fits.-Had his first fit thirteen years ago. The fits gradually increased in frequency. After fits was very restless and intractable.

Record of fits from admission to December 31, 1901.-Day fits, 172 ; night fits, 150 .

For the last seven months all his fits have been nocturnal. Alkalinity in the interparoxysmal period 1.48. Nine hours before a fit, $1 \cdot 43$. Fit 9.30 p.m. Blood 9.50 p.m. alkalinity 1.12 . Blood 10.50 p.m. alkalinity 1.26 . Blood 11.50 p.m. alkalinity $1 \cdot 385$. Blood 10.30 a.m. alkalinity 1.538.

Patient was subjected to the suprarenal treatment for twentyone days, apparently without any effect. The fits did not increase in frequency, and there was no perceptible rise in the blood pressure.

Case 22.-Aged 21, admitted March 22, 1894. Duration of epilepsy, fourteen years. Bodily condition feeble, poorly nourished. Palate high.

No family history obtained.

Mental condition.-Is very simple-minded, is of low intellect, is unable to add simple numbers, rambles incohorently. After fits is irritable, impulsive, and abusive.

History of fits.-Had his first fit when geven years of age. A short time before admission had an attack of status epilepticus. Grand mal, no aura.

Record of fits from admission to December 31, 1901.-Day fits, 531 ; night fits, 162.

Interparoxysmal alkalinity $1.538: 1.48$. Two slight fits 9 a.m. Blood 9.30 a.m. alkalinity $1 \cdot 12$. Blood 11 a.m. alkalinity 1.43 . Blood 1 p.m. alkalinity $1 \cdot 43$. Blood 5 p.m. alkalinity $1 \cdot 59$.

Case 23.-Aged 32, admitted November 8, 1895. Duration of epilepsy, twenty-nine years. Bodily condition fair, suffers from indigestion.

No family history obtained.

Mental condition.-Is dull and feeble-minded; mentel reaction is slow; he is easily excited, and is very unstable. Memory very defective; has very little idea of time or place; after fits is violent and impulsive.

History of fits.-Had his first fit when three years of age, and then had three fits a month up to 14 years of age. He had no fits 
from 14 to 25 , and since the latter age he has had them frequently. Grand mal. Precordial aura, which he describes as "a pleasant feeling as though his heart were stopping."

Record of fits from admission to December 31, 1901. Day fits, 475 ; night fits, 73.

Interparoxysmal alkalinity $1 \cdot 48: 1 \cdot 43$. Alkalinity during aura 1.26 ; alkalinity thirty minutes after fit, $1 \cdot 18$; alkalinity one hour after fit, 1.26 ; alkalinity three hours after fit, 1.43 ; alkalinity six hours after fit, 1.59.

Case 24.-Aged 43, admitted April 30, 1894. Duration of epilepsy, fifteen years. Bodily condition fair; muscular movements very tremulous.

Family history.-Father, mother, and one sister insane at Brookwood Asylum. Brother committed suicide.

Mental condition.-Is dull, morose, and feeble-minded; after fits is restless and wanders aimlessly round the ward; has hallucinations of sight and hearing.

History of fits. - Had his first fit when twenty-eight years of age. Grand mal, no aura. Mental confusion lasts about five hours.

Record of fits from admission to December 31, 1901.-Dry fits, 46 ; night fits, 83.

Interparoxysmal alkalinity $1.538: 1.48$. Three fits from 9 a.m. to 11 a.m. Blood 11.30 a.m. alkalinity 1.0387. Blood 12 noon alkalinity $1 \cdot 26$. Blood 2 p.m. alkalinity 1.43. Blood 5 p.m. alkalinity 1.538 . Blood 10 p.m. alkalinity 1.538 .

Case 25.-Aged 26, admitted October 19, 1893. Duration of epilepsy, six years. Bodily condition fair.

Family history.-Father and mother alive and healthy. No history of insanity, epilepsy, or phthisis.

Mental condition.-Is simple and childish in manner, incoherent in his remarks, expresses delusions of persecution, says "people follow him about to shoot him"; after fits is violent and abusive.

History of fits.-Had his first fit six years ago. It was stated to be caused by a large piece of wood falling on his head. Grand mal; left eyelid twitches three minutes prior to the fit. Mental confusion lasts about four hours.

Record of fits from admission to December 31, 1901 :-Day fits, 115 ; night fits, 411.

Interparoxysmal alkalinity, $1.538: 1 \cdot 43$. Alkalinity during aura, 1·26. Alkalinity fifteen minutes after fit, 1·0387. Alka- 
linity one hour after fit, 1.385. Alkalinity two hours after fit, 1.43. Alkalinity four hours after fit, 1.538. Alkalinity twelve hours after fit, 1.59.

Case 26.-Iged 21, admitted November 1, 1894. Duration of epilepsy, not known. Bodily condition fair; usually constipated.

No family history obtained.

Mental condition.-Is simple and childish in manner and talk. After tits is irritable and quarrelsome, and develops delusions of persecution.

History of fits.-Patient says he has had fits since nine years old. Grand mal; aura two minutes prior to the fit, which he describes as a painful sensation in his right forearm. Mental confusion lests about six hours.

Record of fits from admission to December 31, 1901 :-Day fits, 378 ; night fits, 456.

Interparoxysmal alkalinity, 1.538:1.48. Alkalinity sixty seconds before a fit, $1 \cdot 18$. Alkalinity one hour after, 1.26. Alkalinity two hours after, 1-385. Alkalinity four hours after, 1.538. Alkalinity twelve hours after, 1.59.

Casc 27.-Aged 26, admitted November 3, 1893 . Duration of epilepsy thirteen years. Bodily condition fair. Palate high and arched. Is myopic.

Family history.-Father died of lead palsy, intemperate. Mother alive and healthy. Maternal grandfather died of phthisis.

Mental condition.-Is simple and childish in manner and talk; mental reaction slow. Intellect weak. Memory defective. After fits is troublesome, irritable, emotional and impulsive.

History of fits.-Had his first fit when 13 years of age. Had "brain fever" when 4. Grand mal. Epigastric aura. Mental confusion lasts about four hours.

Record of fits from admission to December 31, 1901. Day fits, 420 ; night fits, 121 .

Interparoxysmal alkalinity 1.48 ; half an hour after two severe fits, alkalinity 1.0387 ; one hour after two severe fits, alkalinity 1.26 ; two hours after two severe fits, alkalinity 1.385 ; four hours after two severe tits, alkalinity 1.533 ; twelve hours after two severe fits, alkalinity 1.59.

Case 28.-Aged 24, admitted January 31, 1902. Duration of epilepsy three years. Bodily condition fair.

Family history. Father and mother alive and healthy. A brother insane, died at Hanwell Asylum seven years ago. One sister insane at Salisbury Asylum. 
Mental condition.-Is simple and childish in manner and talk. Memory defective; is unable to give a coherent account of himself; after tits is very excited.

History of fits.-Developed his epilepsy when 21 years of age. Grand mal, no aura. Mental confusion lasts about five hours. He has had several strong fits since admission.

Interparoxysmal alkalinity, $1.538: 1.48$. Two strong fits 10 a.m. Blood 10.30 a.m. alkalinity 1.0387. Blood 11 a.m. alkalinity 1.26. Blood 1 p.m. alkalinity 1.43. Blood 5 p.m. alkalinity 1.538 . Blood 8 p.m. alkalinity 1.538 .

Case 29.-Aged 27, admitted October 14, 1899. Duration of epilepsy, twenty years. Bodily condition fair. Mitral disease. Usually constipated.

No family history obtained.

Mental condition.-Is dull and feeble-minded, mental reaction slow. Memory defective for recent events. After fits is restless and impulsive.

History of fits.-Had his first fit when 7 years of age, said to follow scarlet fever. Grand mal, no aura. Mental confasion lasts about four hours.

Record of fits from admission to December 31, 1901.-Day fits, 71 ; night fits, 225.

Interparoxysmal alkalinity $1.48: 1.43$. Strong fit 2 p.m. Blood 2.20 p.m. alkalinity $1 \cdot 12$. Blood 3 p.m. alkalinity 1.26. Blood 5 p.m. alkalinity $1 \cdot 48$. Blood 7 p.m. alkalinity 1.538 .

Case 30.-Aged 44, admitted November 4, 1893. Duration of epilepsy, six years. Bodily condition good.

Family history.-Father and mother dead. Two uncles and grandfather died of phthisis.

Mental condition.--Is dull and feeble-minded. Memory much impaired, especially for recent events. After fits is irritable, grumbles much and says his food is poisoned.

History of fits.-Developed his epilepsy when 38 years of age Grand mal, no aura. Mental confusion lasts about five hours.

Record of fits from admission to December 31, 1901.-Day fits, 188; night fits, 219.

Interparoxysmal alkalinity, 1.48. Half an hour after two fits, alkalinity 1.0387 ; one hour after two fits, alkalinity 1.26 ; two hours after two fits, alkalinity 1.43 ; three hours after two fits, alkalinity 1.538 ; five hours after two fits, alkalinity 1.538 ; eight hours after two fits, alkalinity 1.59 . 
Case 31.-Aged 19, admitted Ootober 12, 1893. Duration of epilepsy, ten years. Bodily condition good.

No family history obtained.

Mental condition.-Is very dull and feeble-minded, restless sfter fits, and expresses vague delusions of persecution. Memory very defective.

History of fits.-Grand mal. Mental confusion lasts about three hours.

Record of fits from admission to December 31, 1901.-Day fits, 348; night fits, 762 .

Interparoxysmal alkalinity 1.538. Five fits from 7 a.m. to 10.30 a.m. Blood 11 a.m. alkalinity $\cdot 831$. Blood 1 p.m. alkalinity $1 \cdot 26$. Blood 2 p.m. alkalinity 1.43 . Blood 5 p.m. alkalinity $1 \cdot 59$. Blood 9.30 p.m. alkalinity $1 \cdot 538$.

Case 32.-Aged 44, admitted August 17, 1895. Duration of epilepsy, thirty years. Bodily condition fair; is usually constipated.

No family history obtained.

Mental condition.-Is dull and feeble-minded. Memory much impaired. After fits is troublesome, restless, and impulsive.

History of fits.- Has had fits for 30 years. Grand mal, taste aura. Mental confusion lasts about five hours.

Record of fits from admission to December 31, 1901.-Day fits, 691 ; night fits, 199.

Interparoxysmal alkalinity, $1.538: 148$. Two strong fits 9 a.m. Blood 9.30 a.m. alkalinity $1 \cdot 18$. Blood 11 a.m. alkalinity 1.43. Blood 1 p.m. alkalinity 1.48 . Blood 3 p.m. alkalinity 1.59 . Blood 7 p.m. alkalinity 1.59 .

Case 33.-Aged 23, admitted February 19, 1896. Duration of epilepsy, seventeen years. Bodily condition fair, suffers from indigestion.

Family history.-Father dead, cause unknown. Mother dead, cause heart disease. Patient the only child.

Montal condition.-Is simple and childish in manner and talk; has some religious exaltation with mild excitement.

History of fits.- Had his first tit when six yeurs of age; did not have another for ten years; since that time he has had them frequently. Grand mal, vo aura. Mental confusion lasts three hours.

Record of fits from admission to December 31, 1901.-Day fits, 575 ; night fits, 208.

Interparoxysmal alkalinity, $1 \cdot 48: 1 \cdot 43$. One slight fit 2 p.m. 
Blood 3 p.m. alkalinity 1.385 . Blood 4 p.m. alkalinity $1 \cdot 48$. Blood 6 p.m. alkalinity 1.59. Blood 10 p.m. alkalinity 1.59 .

Case 34.-Aged 40, admitted November 11, 1895 . Duration of epilepsy, twenty-four years. Bodily condition fair; pupils irregular, left contracted.

No family bistory obtained.

Mental condition.-Is dull, confused, and simple-minded. Memory much impaired; has no idea of time; after fits is violent, hears voices, and chatters to them.

History of fits.-Had his first fit when sixteen years of age. Grand mal, no aura. Mental confusion lasts six hours.

Record of fits from admission to December 31, 1901.-Day fits, 77 ; night fits, 352 .

Interparoxysmal alkalinity, $1.538: 1.48$. Three strong fits from 1 p.m. to 2.30 p.m. Blood 2.45 p.m. alkalinity 1.0387. Blood 4.30 p.m. alkalinity 1.385 . Blood 6.30 p.m. alkalinity 1.59. Blood 10.30 p.m., alkalinity 1.538 .

Case 35.-Aged 65, admitted February 1, 1898. Duration of epilepsy, ten years. Bodily condition fair. Arteries very atheromatous, albumen in urine. Has been in the army, and lived twelve years in India. Scar on penis. Scars on both groins.

No family history obtained.

Mental condition.-Is dull and feeble-minded, mental reaction slow. Memory much impaired ; after fits is pugnacious, violent, and abusive.

History of fits.- Had his first tit ten years ago. Grand mal. Epigastric aura. Nental confusion lasts about four hours.

Record of fits from admission to December 31, 1901.-Day fits, 147 ; night fits, 190.

Interparoxysmal alkalinity, 1.662. Alkalinity during aura, 1.26. Slight tit 10 a.m. Blood 10.15 a.m. alkalinity 1.26 . Blood 12 noon alkalinity 1.48. Blood 2 p.m. alkalinity 1.59 . Blood 6 p.m. alkalinity 1.59 .

Case 36.-Aged 54, admitted December 13, 1900. Duration of epilepsy, five years. Bodily condition fair. Mitral systolic bruit, arteries atheromatous.

No family bistory obtained.

Mental condition.-Is simple and childish in manner and talk. Memory much impaired both for recent and remote events. After tits is very troublesome, and rushes wildly about the ward.

Bistory of fits.-Developed his epilepsy about five years ago; 
a week prior to his admission he had four fits. Grand mal, no aura. Mental confusion lasts about five hours.

Record of fits from admission to December 31, 1901.-Day fits, 9 ; night fits, 11.

Interparoxysmal alkalinity, 1.662 . Strong fit at 2 p.m. Blood 2.30 p.m. alkalinity 1.0387 . Blood 3 p.m. alkalinity $1 \cdot 26$. Blood 5 p.m. alkalinity 1.538. Blood 7 p.m. alkalinity 1.59 .

Patient was subjected to the suprarenal treatment for twentyone days; the number of fits was increased, but his mental condition improved.

Case 37. -Aged 18, admitted February 14, 1902. Duration of epilepsy, four years. Bodily condition fair.

Family history.-Father and mother alive and healthy. Paternal aunt insane, died at Banstead Asylum.

Mental condition.-Is dull and simple-minded; mental reaction slow. Memory much impaired for recent events.

History of fits.-Had his first fit when 14 years of age. Grand mal, epigastric aura. Mental confusion lasts three hours. He has had several fits since admission, mostly nocturnal.

Interparoxysmal alkalinity, $1.48: 1.43$. Alkalinity during aura 1.18. One hour after fit, alkalinity 1.26 ; two hours after fit, alkalinity 1.385 ; four hours after fit, alkalinity 1.48 ; six hours after fit, alkalinity 1.538 ; twenty-four hours after fit, alkalinity 1.59 .

Case 38.-Aged 34, admitted May 18, 1900. Duration of epilepsy, seventeen years. Bodily condition fair ; is usually constipated and suffers from indigestion.

No family history obtained.

Mental condition.-Is dull and simple-minded. Memory much impaired, especially for recent events. After fits is restless, impulsive, and develops persecutory delusions.

History of fits.-Had his first fit when 17 years of age. Grand mal. Ocular aura about two minutes prior to the fit. Mental confusion lasts about four hours.

Record of fits from admission to December 31, 1901.-Day fits, 88 ; night fits, 35.

Interparoxysmal alkalinity, $1.538: 1.43$. Alkalinity during aura 1.26. Fit 4 p.m. Blood 4.15 p.m. alkalinity $1 \cdot 12$. Blood 5 p.m. alkalinity $1 \cdot 26$. Blood 7 p.m. alkalinity $1 \cdot 43$. Blood 11 p.m. alkalinity 1.48 .

Case 39.-Aged 44, admitted May 29, 1899. Duration of epilepsy not known. Bodily condition fair. 
No family history obtained.

Mental condition.-Is dull and feeble-minded. Memory very defective, has no idea of time. After fits is excited, impulsive and very fond of making accusations against the attendant.

History of fits.-Grand mal, epigastric aura. Mental confusion lasts about six hours.

Record of fits from admission to December 31, 1901. Day fits, 104 ; night fits, 134.

Interparoxysmal alkalinity, $1.48: 1.43$. Strong fit, 1 p.m. Blood 1.20 p.m. alkalinity 1.0387 . Blood 3 p.m. alkalinity $1 \cdot 385$. Blood 4 p.m. alkalinity 1.48 . Blood 8 p.m. alkalinity 1.538 . Blood 1 a.m. alkalinity 1.538.

Case 40.-Aged 28, admitted October 25, 1893. Duration of epilepsy, thirteen years. Bodily condition fair. Suffers from indigestion, frequently constipated.

Family history.--Father alive and healthy. Mother slive, very simple and eccentric. Mother's brother died in an asylum. Patient the only child.

Mental condition.-Is very simple and childish in menner and talk, und dirty in his habits. Memory very defective; after fits is restless and intractable.

History of fits.-Developed his epilepsy when 5 years of age. Grand mal. Mental confusion lasts about three hours.

Record of fits from admission to December 31, 1901. Day fits, 490 ; night fits, 998.

Interparoxysmal alkalinity $1.538: 1.48$. Fit 10 a.m. Blood 11 a.m. alkalinity $1 \cdot 26$. Blood 1 p.m. alkalinity $1 \cdot 48$. Blood 3 p.m. alkalinity 1.538 . Blood 5 p.m. alkalinity 1.538 . Six fitsnocturnal-3 a.m. to 4.30 a.m. Blood 11 a.m. alkalinity 1.48 . Blood 12 noon alkalinity 1.59. Blood 5 p.m. 1.538.

\section{General Considerations.}

These results show clearly and consistently that the alkalinity of the blood in epilepsy undergoes marked variations. These variations manifest themselves in a diminution.

I.-The average alkalinity during the interparoxysmal period is lower than the average of the control cases.

II.-There is a sudden and pronounced fall immediately prior to the onset of the fit.

III.-There is a further diminution after the fit is over. 


\section{I.-The Interparoxysmal Diminution.}

All the cases studied showed this diminution with the exception of No. 35 and No. 36 .

In these two cases the alkalinity was normal and varied within physiological linits. This is explained by the fact that they are senile cases with arterial degeneration and alcoholic histories, having developed their epilepsy after forty years of age, and are cases of symptomatic epilepsy.

The interparoxysmal diminution varied in several of the cases, and it was more marked in cases suffering from gastric catarrh and constipation, e.g., Cases $3,32,37$, \&c. The diminution is progressive right up to the epileptic discharge, immediately prior to which there is a marked fall.

How to interpret this gradual and progressive diminution is a matter of some difficalty; the constancy of the dimination is so much in evidence that the possibility of accidental occurrence, from such concurrent diseases as anæmia, gout or rheumatism, in which the alkalinity is lowered, is ruled out (and this period in an epileptic's life is one of comparative bealth), and, on the other hand, the constancy with which the alkalinity is maintained within physiological limits in health is equally so well marked that the question naturally arises: What is the cause of the diminution?

(a) It may be explained by the gradual accumulation of toxines of an acid nature in the blood. It is interesting and instructive to note that the lowest values of alkalinity were obtained from cases suffering from gastric catarrh and constipation. Various alienists have drawn attention to the fact that gastric and intestinal troubles bear some relation to the epileptic attack, as under these conditions the fits are more frequent. Agostini (13) advanced the theory that the exciting cause is a toxin absorbed from the alimentary canal ; by correcting these disorders he found much benefit, and considerable diminution in the number of fits. In gastric and intestinal catarrh there is a condition of hyperacidity both in the stomach and the intestines. The hyperacidity is due to the presence of the organic acids, lactic, acetic, and butyric acids. These acids are absorbed, pass into the circu- 
lation, and diminish the alkalinity of the blood. The writer has on several occasions raised the alkalinity in these cases by giving hydrarg. subchlor. gr. 5 and an antacid mixture. There is ample evidence to show that the alimentary canal is a fruitful source of toxines, which are absorbed into the blood, and by reacting on the organism bring forth abnormal manifestations of activity.

(b) It may be the result of deficient metabolism. The alkalinity of the blood is that of the body tissues generally, and the sum total of the metabolism of the body results in en alkaline reaction. Thus in epilepsy the general metabolism may be below par, with the result of a diminished value of the alkalinity of the blood, due either to a deficient amount of alkali or an excess of acid substances.

\section{II.-The Sudden and Prononnced Fall Immediately Prior to the Onset of the Fit.}

This phenomenon was observed in fifteen of the cases, and the blood was taken from ten seconds to two minutes before the fit. It may be regarded as the bio-chemical aura of the epileptic fit and a manifestation of some morbid change or changes taking place in the organism.

When the quantity of blood in the body (one-twelfth to one-fourteenth of the body weight), is taken into consideration, the amount of acid required to diminish the alkalinity must be relatively great, also the particular source or sources of the acid products must be qualitatively or quantitatively active. The most likely origin of these acid products are (a) neuronic; (b) muscular.

(a) The neuronic origin.-The neurones, like other cells in the body, undergo metabolic activity, and their functional activity depends upon a chemical change, a disintegration of food into chemical end products-carbonic and sarcolactic acids. The amount of acid formed must be infinitesimal; it is a case of the most highly developed cells evolving the maximum of work with the minimum formation of waste products.

The explanation of the sudden diminution by the acid 
products of neurone metabolism seems very fallacious. The neurones concerned in an epileptic seizure are those of the Rolandic area-a cubic inch at most on either side-and the acid products formed by their activity cannot be sufficient to lower the alkalinity of a gallon of blood, which means an enormous quantity of acid. It requires 1.662 grammes of $\mathrm{H}_{2} \mathrm{SO}_{4}$ to neatralise the alkalinity of $1,000 \mathrm{cc}$. of blood seram, and in order to neutralise the alkalinity of the total amount of blood serum, requires roughly about 4 grammes of $\mathrm{H}_{2} \mathrm{SO}_{4}$-in fact, it seems very improbable that all the cells of the cerebral cortex, say 20 grammes, can produce acid substances equal to 4 grammes of $\mathrm{H}_{2} \mathrm{SO}_{4}$. The acid products of neurone metabolism are much weaker, consequently the amount would have to be greater. On this calculation it is impossible for the neurones to produce such an amount of acid from so small a source.

Further, if this diminution in the alkalinity is due to these neuronic chemical end products, what is the condition of affairs with regard to the cerebro-spinal fluid? Compared with the volume of the blood it is scanty (the amount present is about two ounces), and the reaction would therefore necessarily be acid. But an acid medium is incompatible with the life of the neurone. The immediate surroundings are alkaline, the cerebro-spinal fuid which bathes and comes into such close contact with the neurones is alkaline, the blood is alkaline, the neurones themselves have an alkaline reaction, the sea in which they live is alkalive, and the river which flows into the sea has an alkaline reaction. This suggests that for physiological neuronic activity an elkaline medium is essential. Even an excessive, abnormal, or disordered cerebral metabolism will not account for the production of this diminution directly, and for the above reasons the neuronic origin of the sudden drop cannot be maintained.

(b) The muscular origin.-The most important metabolic tissues in the body are the muscular and the glandular. Of the two, the former is the more active; this is so because it is the most abundant, and forms about 42 per cent. of the body weight. The muscles produce by 
their activity the greater part of the body heat. Even during relative repose such as sleep the muscles are the seat of chemical changes, and produce a sufficient amount of heat to keep up the body temperature; also in functional paralyses where the metabolic processes in the muscles are not impaired by organic disease and the afferent and efferent channels are intact the nutrition of the muscles is relatively little impaired. The metabolism of the mascular tissue is under the control of the nervous system, and when the nervous system fails muscular metabolism is interfered with and the body temperature falls.

What has been stated above with reference to the production of heat, may be equally affirmed regarding the production of the chemical end products of muscular metabolism.

The preliminary chemical change is an oxidation, resulting in the formation of inogen, and the muscular contraction is a consequence of the disruption of this inogen, which is the first event in the response of a muscle to stimulation. It is a debatable point whether this chemical change is directly transformed into the mechanical energy which manifests itself in the muscular contraction. The large bulk of muscle engaged in the violent convulsions of an epileptic seizure is an ample source for the altered reaction of the blood. That the major part of the fall should occur before the visible and violent spasms of the convulsions appear, is consequently explicable on the following considerations:-

(I.) The muscles normally, even when at rest, are the seat of metabolic activity, and produce the bulk of the body heat.

(II.) During violent exercise, the extra amount of heat produced is only a proportion of the amount of heat required to keep the body temperature within normal limits.

(III.) The chemical change is the forerumner of the muscular contraction.

(IV.) The sensori-motor areas of the cerebral cortex control the metabolism of the muscles, as is evidenced by functional paralyses, muscular tonus, and section of the spinal cord with a consequent fall in the body temperature.

It is therefore probable that there is a considerable alteration in the metabolism of the cerebral neurones, with 
consequent hyperexcitability and decreased inhibition some time prior to the actual epileptic discharge. This modified cortical activity brings about an increase of the metabolism which occurs prior to the visible spasms, and accounts for the sudden and pronounced diminution during this period.

\section{III.-The Further Diminution after the Fit is over.}

This diminution is well marked and was found in all the cases except after petit mal seizures. It is apparent soon after the fit is over, three to ten minutes, and lasts for some hours; the alkalinity gradually rises, the rise being more marked in the first hour. The return to normal varies in the different cases, but on an average takes from four to five hours. The explanation of this diminution is not far to seek. It is directly due to the acid products of muscular metabolism-carbonic and sarcolactic acids-generated during the violent tonic and clonic spasms of the muscles during the epileptic paroxysm. This phenomenon is physiological, and is seen, though in a less degree, after severe muscular exercise. The variations met with in the different cases depend upon the frequency and the number of the fits, and on the duration and the severity of the muscular twitchings. Thus, after one slight fit, the fall in alkalinity is $6^{\circ}$; after four fits, 8,9 or $10^{\circ}$. Then again, this diminution is negligeable in cases of petit mal. These facts, together with the appearance of the fall after the spasms are over, and the gradual rise to the normal, seem to prove that the whole diminution is muscular in origin.

The relation of the dimiuution to the number of fits and to the duration and severity of the muscular contractions, holds good to a certain point, but the writer has taken blood from a patient who had forty fits in the short space of an hour, and from another patient after five fits, and has found the alkalinity to be of the same value, e.g., 6925 . This points to a limit in the diminution.

The rapidity of return of the alkalinity to normal varies in the different cases, and in some cases, Nos. 3 and 4, the return was quick. Certain facts observed in these cases may account for the quick recovery: (a) free voiding of 
urine; (b) free perspiration; (c) leucocytosis-the greater the leucocytosis the sooner the recovery. The ultimate end of these acid products may be accounted for by excretion. They may be destroyed by the increased number of leucocytes, or they may be used as food by some of the other tissues, or neutralised by the secretions of the glands. It was also observed that the return to normal bears a relation to the mental confusion of the patient after the attack: in Case 3 , where the return to normal alkalinity is comparatively rapid, the mental recovery is also rapid; in Case 1, whose mental recovery is slow, the alkalinity keeps at a low value.

The effect of drugs upon the alkalinity is transient, and it is impossible to elevate and maintain the alkalinity within physiological limits for any appreciable length of time. The bromides elevate the alkalinity even to the normal of the control cases for a certain time, but on continued administration, and even when the dose is increased, the alkalinity falls. The best results were obtained from strontii bromidi, sodii bicarb. aa. gr. 15 ter in die; for some time the alkalinity was maintained at a high value, but only to fall again.

In the case of No. 3, a rectal enema of potas. brom. gr. 30 , chloral hydratis. gr. 20 , given after twenty-four fits, raised the alkalinity from 831 to $1 \cdot 385$. This was maintained for forty-five minutes, after which it dropped again to 1.0387 , and gradually attained its normal value in four hours.

Suprarenal extract has apparently little effect upon the alkalinity. The effect upon the mental state was good, and all the patients subjected to the treatment recovered from their mental confusion much sooner. One of the cases, No. 4, improved considerably; usually after a fit he has a headache for some hours, but when taking suprarenal he did not have headaches. In all the cases the number and frequency of the fits were much increased, and on this account the treatment was stopped. These results are very different to those obtained by Dr. Fill (14).

The exact role which a diminution in the alkalinity of the blood plays in the production of the epileptic attack is difficult to estimate. It is of the utmost importance for any 
cell in the body to have a proper, adequate, and pare supply of blood, and this applies especially to the cerebral neurones, as they are extremely sensitive to a change in environment. This is well seen in the case of toxic agents circulating in the blood. As has been stated before, the conditions under which the neurones functionate is one of alkalinity, and it does not seem strange that any appreciable diminution in the alkalinity of their surroundings may bring about abnormal manifestations of activity. This applies with greater force in the case of the unstable, readily explosive, epileptic neurones. The writer has obtained good results in the treatment of epilepsy by maintaining the alkalinity of the blood within physiological limits; by doing so the number of fits is much diminished. Unfortunately it is impossible to elevate and maintain the alkalinity by the administration of drugs.

\section{THE LeUcocytes.}

\section{I.-The Interparoxysmal Period.}

There is a wide variation in the number of leucocytes. In some cases, the leucocytes were found to drop some hours before a fit. In other cases, the leucocyte count was low daring the interparoxysmal period. These were cases who had frequent fits. In others, and these constitated the majority, there was a gradual drop right up to the paroxysm. A probable deduction is that the number and the activity of leucocytes depend upon the health of the epileptic in this period, that as the alkalinity of the blood diminishes and the nearer the patient is to his paroxysm, the lower is the leacocyte count, and the less the activity.

\section{II.-After the Fit.}

There is a distinct leucocytosis which shows itself a short time after the fit, and gradually increases, attaining its maximum from about fifty to seventy minutes after. The increase is due to the large and small hyaline cells. In the analysis of the leucocytes, the polymorphonuclear cells are diminished. The large hyaline cells are increased. The small byaline cells are much increased. The eosinophiles are increased from two to ten hours after the attack. 
The leucocytosis in the status epilepticus is not so constant, and is subject to wide variations. It takes a longer time to appear and is not so pronounced as after one individual fit. In one case, 45,000 leucocytes were counted after two fits. In another, 30,000 were counted after thirty fits in quick succession. In another case of status 12,000 white cells were counted after eighty-five fits.

The leucocytosis passes off gradually and undergoes the changes described under the interparoxysmal period. With regard to the causation, the consensus of experimental evidence seems to show that leucocytosis is to be looked upon as the reaction produced by a chemical substance circulating in the blood, and has its special mission to perform, e.g., the removal or destraction of these substances. On this hypothesis, the leucocytosis following the epileptic fit may be explained. The increase of the eosinophiles some hours after the attack is much in evidence, and is also very constant, and it is probable that these cells complete the destruction of the waste products by means of their secretory functions.

\section{Conclusions.}

(1) The alkalinity of the blood in the interparoxysmal period is lower than the average of the control cases.

(2) The diminution is gradual and progressive, and is more marked in those cases suffenng from gastric catarrh and constipation.

(3) There is a marked sudden and pronounced fall immediately prior to the onset of the fit.

(4) There is a further fall in the alkalinity after the fit is over; this diminution is seen from three to ten minutes after the attaok.

(5) This after-dimination depends upon the duration and severity of the muscular twitching, and upon the degree of the alkalinity in the interparoxysmal period.

(6) There is a gradual return of the blood to its normal alkalinity, which takes place in five to six hours, the rise being more marked in the first hour. 
(7) If the alkalinity keeps at a low value, it may determine the onset of another fit.

(8) The dimination after the fit is due to the chemical end products of muscular metabolism, i.e., sarcolactic and carbonic acids, and not to sabstances in direct relation to the epilepsy.

(9) The diminution after a nocturnal fit takes a longer time to return to the normal than the diminution after a day fit.

(10) It is impossible to elevate and maintain the alkalinity within physiological limits for any appreciable length of time by the administration of drugs.

(11) There is a leucocytosis after a it. The increase is due to the small hyaline cells, also to a less extent to the large hyaline cells. The polymorphonuclear cells are diminished. There is an increase in the eosinophile cells some hours after the altack.

(12) The leucocytosis is not so pronounced in status epilep ticus ; it diminishes with each seizure.

\section{TABLE I.}

Alkalinity of the Control Cases.

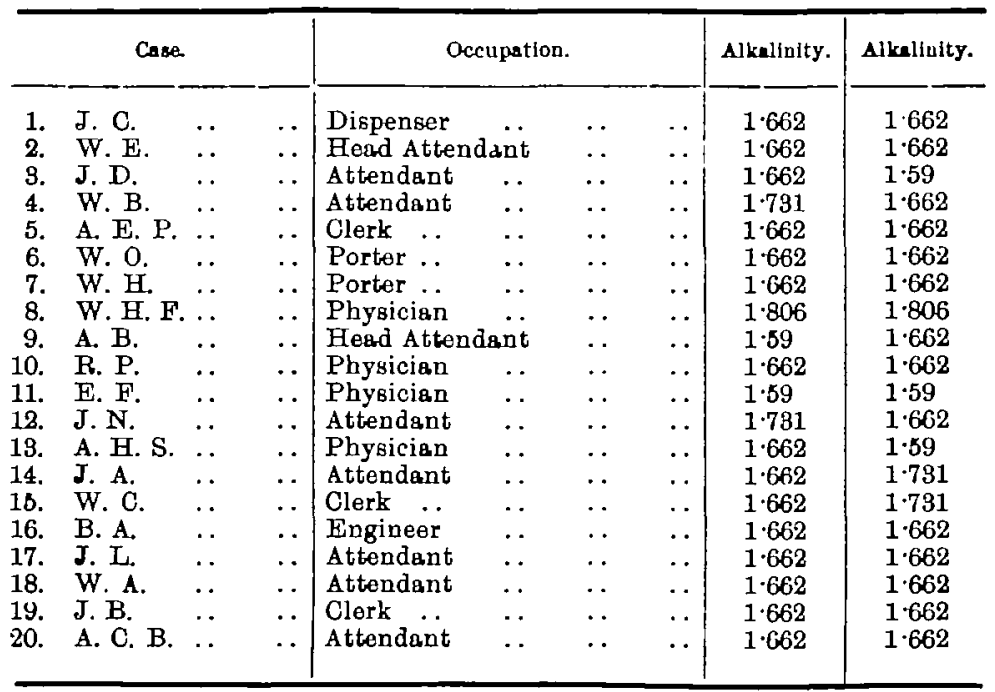


Table showing the Alkalinity during the Aura and Varying Periods after Paroxysm.

\begin{tabular}{|c|c|c|c|c|c|c|c|c|c|c|}
\hline & & & Aura. & $\begin{array}{c}10-80 \\
\text { Minutes. }\end{array}$ & Hour. & $\stackrel{2}{\text { Hours. }}$ & $\begin{array}{c}\mathbf{3} \\
\text { Hours. }\end{array}$ & $\begin{array}{c}4 \\
\text { Hours }\end{array}$ & $\begin{array}{c}5-12 \\
\text { Hourm }\end{array}$ & $\begin{array}{c}12.94 \\
\text { Hours }\end{array}$ \\
\hline ase & 1, 7 fits & & 一 & 0387 & $1 \cdot 26$ & $1 \cdot 985$ & $1 \cdot 43$ & - & - & 1.43 \\
\hline " & & & - & & $1 \cdot 18$ & - & 1.48 & $1 \cdot 48$ & $1 \cdot 48$ & 140 \\
\hline ", & & & - & 891 & $1 \cdot 12$ & $1 \cdot 385$ & - & - & 1.49 & $1 \cdot 48$ \\
\hline$"$ & - & . & $1 \cdot 26$ & $1 \cdot 18$ & $1 \cdot 985$ & 1.43 & & $1 \cdot 598$ & & $\ldots$ \\
\hline$"$ & $2,1 \mathrm{f}$ & .. & 一 & - & - & - & 1.385 & - & $1 \cdot 538$ & - \\
\hline ," & $a$ & . & - & $\overrightarrow{0}$ & 1.26 & $1 \cdot 385$ & $1 \cdot 48$ & - & 1.59 & - \\
\hline ," & & .. & $1 \cdot 26$ & $1 \cdot 18$ & $1 \cdot 385$ & 1.48 & 一 & 1.598 & - & - \\
\hline ", & $3,8 \mathrm{f}$ & .. & - & 891 & $1 \cdot 26$ & $1 \cdot 385$ & - & $1 \cdot 48$ & - & - \\
\hline " & $f f$ & $\because$ & - & $1 \cdot 18$ & $1 \cdot 985$ & $1 \cdot 26$ & 一 & $1 \cdot 48$ & - & - \\
\hline " & & .. & - & $\cdot 891$ & $1-26$ & - & 一 & - & - & 1.538 \\
\hline ," & 4,1 & $\ldots$ & - & 1.0987 & 1.26 & $1 \cdot 43$ & - & - & $1 \cdot 598$ & - \\
\hline ," & 5, & . & - & 891 & $1-26$ & $1 \cdot 385$ & - & 1.48 & - & $1 \cdot 662$ \\
\hline ", & 6 & .. & $1 \cdot 26$ & - & $\overline{-}$ & - & - & - & - & - \\
\hline ," & 6,2 & . & 一 & $1 \cdot 09887$ & 1.26 & $1 \cdot 43$ & 一 & - & 1.538 & - \\
\hline " & 7,1 & . & - & $\cdot 18$ & $1 \cdot 26$ & - & - & - & - & - \\
\hline ", & 0.1 & .. & - & .0387 & 1.26 & - & 1.43 & $=$ & 1.598 & - \\
\hline ", & 8,1 & $\cdots$ & - & -12 & 1.385 & $1 \cdot 48$ & 一 & 1.538 & - & - \\
\hline 3 & 9,1 & .. & $1 \cdot 26$ & $1 \cdot 18$ & $1 \cdot 385$ & $1 \cdot 43$ & - & - & $1 \cdot 538$ & - \\
\hline , & $10,1 \mathrm{fl}$ & .. & . - & $\overline{-}$ & - & - & 1.385 & - & 1.538 & - \\
\hline$"$ & 1 fi & 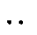 & - & $1 \cdot 12$ & - & $1 \cdot 385$ & - & - & 1.538 & - \\
\hline ,", & 2 & .. & - & $\cdot 881$ & $1 \cdot 12$ & $1 \cdot 26$ & 一 & $1 \cdot 48$ & - & - \\
\hline ", & 11,1 & & 1.985 & $1 \cdot 18$ & 1.985 & $1 \cdot 48$ & - & 1.538 & - & - \\
\hline$\therefore$ & $12,1 \mathrm{f}$ & .. & - & $1 \cdot 885$ & 一 & $1 \cdot 48$ & 1.598 & - & & - \\
\hline ," & $3 \mathrm{fi}$ & .. & - & $\cdot 831$ & $1 \cdot 12$ & $1 \cdot 26$ & - & 1.43 & $1 \cdot 48$ & - \\
\hline ", & 18,2 & & - & $\cdot 12$ & $1 \cdot 26$ & - & 1.48 & $1 \cdot 48$ & - & - \\
\hline " & 14 & . & $1 \cdot 385$ & $\cdot 12$ & - & $1 \cdot 385$ & . & $1 \cdot 48$ & 1.59 & - \\
\hline ," & 15 & 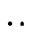 & - & .26 & $1 \cdot 385$ & $1 \cdot 48$ & - & 1.59 & - & - \\
\hline , & & & - & 12 & $1 \cdot 26$ & & $1 \cdot 48$ & - & $1 \cdot 59$ & 1.59 \\
\hline ," & 17 & . & - & 1.0987 & - & $1 \cdot 385$ & $1 \cdot 48$ & - & 59 & - \\
\hline 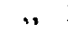 & 18 & & 一 & - & 126 & $1 \cdot 885$ & - & $1 \cdot 48$ & 1.59 & - \\
\hline , & 19 & & - & & $1 \cdot 385$ & $1 \cdot 43$ & 一 & $1 \cdot 48$ & 1.59 & $\cdots$ \\
\hline ,. & 20 & & - & 0987 & $1 \cdot 26$ & $1 \cdot 43$ & - & $1 \cdot 59$ & - & 1.59 \\
\hline 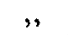 & & & - & 12 & $1 \cdot 26$ & $1 \cdot 385$ & 一 & - & - & $1 \cdot 598$ \\
\hline ", & 22 & . & - & 12 & 一 & $1 \cdot 43$ & - & $1 \cdot 49$ & 1.59 & - \\
\hline 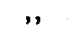 & 28, & & $1 \cdot 26$ & 18 & $1 \cdot 26$ & - & 1.43 & - & 1.59 & - \\
\hline ", & 24, & .. & - & 1.0387 & $1 \cdot 26$ & - & 1.49 & - & 1.538 & - \\
\hline$\therefore$ & 25 & .. & $1 \cdot 26$ & 1.0987 & $1 \cdot 385$ & 1.43 & - & $1 \cdot 588$ & - & 1.59 \\
\hline 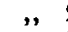 & & & $1 \cdot 18$ & 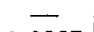 & $1 \cdot 2$ & 1.385 & — & 1.538 & - & 1.59 \\
\hline " & 2 & & - & 387 & $1 \cdot 26$ & $1 \cdot 385$ & - & $1 \cdot 598$ & - & 1.59 \\
\hline " & 2 & & - & $1 \cdot 0.987$ & 1.26 & - & 1.48 & - & 1.538 & - \\
\hline 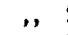 & 2 & & - & $1 \cdot 12$ & $1 \cdot 26$ & - & 1.48 & - & 538 & - \\
\hline$"$ & 30 & . & - & 1.0387 & $1 \cdot 26$ & $1 \cdot 49$ & 1.538 & - & 538 & - \\
\hline & 81 & & - & .831 & $1 \cdot 26$ & 49 & - & - & 1.59 & $1 \cdot 598$ \\
\hline$"$ & 32,2 & & - & $1 \cdot 18$ & - & $1 \cdot 43$ & - & 1.48 & 59 & - \\
\hline ", & & & 一 & - & $1 \cdot 985$ & 1.48 & - & 1.59 & $1 \cdot 5$ & - \\
\hline 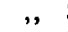 & & & 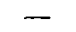 & $1 \cdot 0387$ & - & 1.985 & - & 1.59 & 1.598 & - \\
\hline . & 35 & & 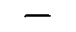 & $1 \cdot 26$ & - & $1 \cdot 48$ & - & 1.59 & 1.50 & - \\
\hline & & & - & $1 \cdot 09887$ & $1 \cdot 26$ & - & 1.538 & - & 1.59 & - \\
\hline " & 37,1 fit & & $1 \cdot 18$ & - & $1 \cdot 26$ & $1 \cdot 885$ & - & $1 \cdot 48$ & 1.588 & 1.59 \\
\hline "' & fi & & $1-26$ & $1 \cdot 12$ & $1 \cdot 26$ & - & & - & 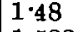 & 一 \\
\hline & & & - & 1.0387 & - & $1 \cdot 985$ & $1 \cdot 48$ & - & 1.588 & - \\
\hline & 40,1 fit & & - & - & $1 \cdot 26$ & - & $1 \cdot 48$ & - & $1 \cdot 538$ & - \\
\hline$"$ & 6 fits & $\cdots$ & - & - & - & - & - & - & $1 \cdot 48$ & 1.59 \\
\hline
\end{tabular}




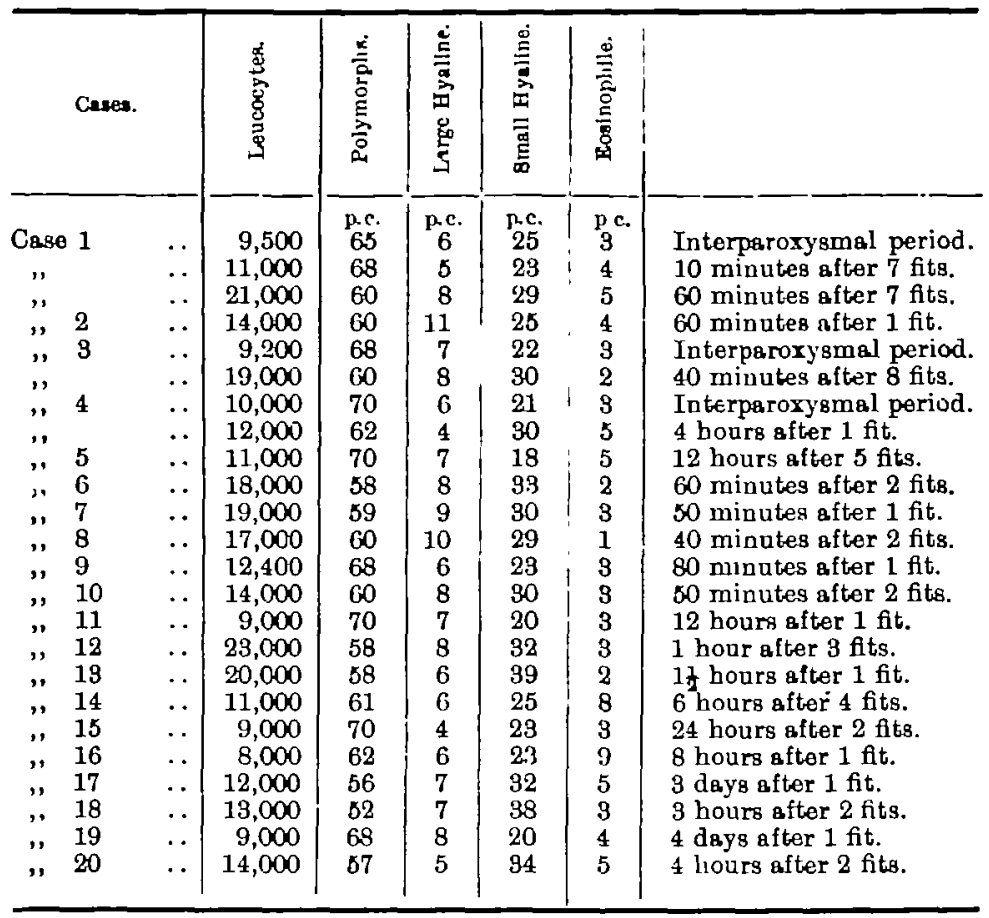

\section{References.}

(1) Luntz. Centrabblatt für die Medicinischen Wissenschafton, 1867.

(2) Lassar. Archiv. fir die gessanmite Physiologie, Band xviii.

(3) Leibrach. "Berichte der Deutschen Chemischen Gesellschaft Bl.," p. $48,1869$.

(4) Landors. "Rial Encyclopedie," iii., p. 161, 1885.

(5) Clifford Allbott. " "System of Medicine." vol. v., p. 448.

(6) Lancet, vol. ii., 1897, p. 719.

(7) "Schüfer's Physiology," vol. i., p. 719.

(8) Cha ron ет Brche. Archives de Nezrologie, 1897, p. 24.

(9) Lo1. Revista sper de Frenialria, 1898, p. 1.

(10) Clifford Allbutt, vol. v., p. 416.

(11) RUtherbord Macphail. "Hack Tuke's Dictionary of Paychological Medicine," Disenses of the Blood.

(12) Kвотивмtlles. Revue de Medicine, 1898.

13) Agostini. Revista Sper de Freniatria, $10 \hat{96 .}$

(14) HiLL. Bulletin of the Laboratory of Mount Hope Retreat, 1899, p. 49. 